\title{
Script Usage in Standardized and Customized Service Encounters: Implications for Perceived Service Quality
}

\author{
Liana Victorino \\ Peter B. Gustavson School of Business \\ University of Victoria \\ PO Box 1700 STN CSC \\ Victoria, British Columbia V8W 2Y2, \\ Canada \\ lianav@uvic.ca
}

\author{
Don G. Wardell \\ David Eccles School of Business \\ University of Utah \\ 1645 E. Campus Center Dr. \#102 \\ Salt Lake City, Utah 84112, USA \\ don.wardell@utah.edu
}

\author{
Rohit Verma \\ School of Hotel Administration \\ Cornell University \\ 338 Statler Hall \\ Ithaca, New York 14850, USA \\ rohit.verma@cornell.edu
}

\begin{abstract}
This study examines the effect that verbal scripts have on customer perceived service quality for two distinct service process types. We designed a video experiment that varied the level of verbal scripting for standardized and customized service encounters. We found that in standardized service encounters, an increase in the level of verbal scripting had no effect on perceived service quality. However, for customized encounters, perceived service quality was impacted. More specifically, a predominantly scripted encounter for customized service processes, on average, resulted in the lowest perception of service quality by respondents. Since verbal scripting was shown to impact customer perceptions of service quality, we suggest that a service provider’s decision regarding the degree of verbal scripting is an important service design consideration.
\end{abstract}

Keywords: service script; service design; service quality; service encounter; video experiment 


\section{Script Usage in Standardized and Customized Service Encounters: Implications for Perceived Service Quality}

\section{Introduction}

A service encounter is the interaction between a frontline employee and a customer (Czepiel et al. 1985, Shostack 1985, Solomon et al. 1985). It is often at this "moment of truth" that the customer makes a critical assessment and evaluates the service (Carlzon 1987). Thus, it is imperative that the employee and customer interaction is carefully designed, managed, and controlled. A common approach used to design the service encounter is to translate within a service script the role and actions employees are to follow when interacting with customers.

Acting as a detailed behavioral guide for employees, the script may specify task requirements

(e.g., the sequence of tasks to be completed) or include exact words or phrases for employees to use when interacting with customers (e.g., "It was a pleasure serving you”) to achieve the organizationally desired service interaction. Therefore, scripts can serve a dual function: (i) to specify the tasks to be completed (such as stipulations about the number of tasks to be performed, the sequence of their occurrence, or the timing associated with completing particular tasks); and (ii) to act as a behavioral cue for employees by detailing the acceptable verbal exchange to occur during the encounter.

Our study focuses on scripting the verbal aspects of the employee's role, or the managerially defined specifications of what to say to every customer. In practice, the use of verbal scripting can be applied in various forms, from being very rigid to more flexible (Tansik and Smith 1991), based on how strictly management expects employees to follow the script (Leidner 1993). These varying degrees of flexibility for employee verbal discretion can be used to design different types of service processes such as standardized or customized encounters. Standardized encounters represent service processes designed to gain economies of scale (or higher volume) whereas the customized encounters represent services processes designed for economies of scope (or higher variety) (e.g., Hayes and Wheelwright 1984, Schmenner 1986). While in reality service processes typically include components of both scale and 
scope, for the purposes of discussion within this article, we investigate two scenarios—one that is standardized and the other that is customized.

Given the inherent characteristics of standardized and customized processes, one may assume that a standardized encounter must be highly scripted in terms of verbal specifications, but this is not necessarily the case. The nature of service processes are largely driven by customer demands of the system, while the decision to verbally script is the provider's preference of how to meet customer needs best during the process. For example, encounters which have high customer volume and similar customer requests are typically designed as standardized processes, but the employee might not follow a strict guide that defines the words and phrases that should make up that standardized encounter. Therefore, the service provider may use different forms of verbal scripting regardless of the service process nature. Conceptually, it has been proposed that the use of scripting should be adapted dependent upon the nature of the service encounter (e.g., McCarthy et al. 2010, Tansik and Smith 1991). Our interest is to assess the impact on perceived quality by customers of different verbal scripting strategies (that we refer to as predominant, moderate, and relaxed cases of verbal scripting) when used within different service process types (namely, standardized and customized).

Operationally speaking, the use of service scripts provides assurance of a particular quality level by employees (Leidner 1993, Stewart 2003). Basically, a script, when used effectively, ensures that employees treat customers properly and prevents task errors from occurring (Chase and Stewart 1994, Stewart 2003). Thus, it is not surprising that the use of scripts has been suggested as a way to implement “fail-safing” mechanisms for service design (Chase and Stewart 1994). Scripting an encounter can also support the employee to appropriately respond to variations that customers introduce to the interaction (Frei 2006). A script therefore provides managerial control over the service encounter, assures a consistent service level, reduces variability, and serves as a standard for employees to follow when interacting with customers.

While the operational implications, all of which impact quality, have been described in past literature, to our knowledge little work has been done to understand how customers actually perceive the 
quality of a scripted encounter. Even scholars outside the operations management discipline note the scarcity of research that empirically assesses service scripting (e.g., Groth et al. 2006). In particular, it is unclear if the use of a service script by employees has a positive, negative, or negligible effect on service quality as perceived by customers.

We were motivated to assess customer perceptions of quality rather than the impact of other relevant operational variables because customers are the ultimate judges of the overall success or failure of a service design decision. Service operations scholars continue to note the importance of understanding how customers perceive the encounter and encourage the incorporation of their perceptions into the design of the service experience (Chase and Dasu 2001, Zomerdijk and Voss

2010). In addition, the "service profit chain” has linked internal decisions such as job design and training tools used in the service delivery system (e.g., scripting strategy) with customers' views of the encounter (e.g., perceived service quality), and designing encounters that meet customer needs has been linked to such important outcomes as customer loyalty and revenue growth (Heskett et al. 1994). Therefore, we believe it is imperative to understand the relationship between the internal decision to script and the external impact scripting has on customer perceived service quality.

This article extends the extant scripting research by directly assessing customer perceived quality as a function of verbal script intensity for two types of service processes that are primarily based on scale and scope considerations (i.e., standardized and customized). We do so by using a video experiment, which is a quite informative and novel approach within the operations management discipline (e.g., Seawright and Sampson 2007). Using an experimental setting, our objective is to gain insights related to the components of service design (i.e., verbal script intensity) used for different types of encounters (i.e., processes) and test their relationship with customer perceptions (i.e., service quality). Such in-depth research has been advocated by leading scholars and editors within the operations management discipline (e.g., Metters and Marucheck 2007, Roth 2007, Roth and Menor 2003).

The remainder of this article is organized in the following manner. First, we review past research that supports our conceptual framework and develop hypotheses. Second, we describe the research design 
and video methodology used. Next, we present the results from the video experiment. We conclude with a discussion of the findings and provide academic and managerial insight for service design.

\section{Background and Hypotheses}

In this section we discuss the conceptual background and develop testable hypotheses for our study. We start with an overall description of how other disciplines have examined scripting by reviewing research about scripts and routines. We also discuss research related to understanding the independent variables manipulated within the experiment. Finally, the conceptual framework is presented and a set of hypotheses is generated.

\subsection{Scripts}

To provide a conceptual background for scripting within a service context, we must review research from disciplines outside the operations management realm. Initially, scripts were discussed in the psychology literature, where a person's decision making and behavioral choices have been deemed to be a result of the script they followed (Abelson 1976). A script from this perspective is “.... coherent sequence of events expected by the individual, involving him either as a participant or as an observer" (Abelson 1976, p. 33). This form of script is a mental schema that is engrained from past experiences.

Script theory has often been applied in services to support conceptual models and propositions about role understanding and the evaluation of service encounters (Bateson 1985, Bitner et al. 1994, McCallum and Harrison 1985, Smith and Houston 1983, Solomon et al. 1985). Solomon et al. (1985) described how scripting identifies role expectations for the encounter. They proposed that customer satisfaction in a service encounter is dependent on the congruence between perceived and expected behaviors by role participants. Smith and Houston (1983) similarly stated that service encounters that occur frequently will form stereotyped sequences of likely events for the customer. These scripts form a person's expectation for a service and are the basis for his or her evaluation of a service experience. These expectations include, “... an anticipation of the service provider’s role and of the probable behavior 
sequence and...” provide “...a comparison level against which outcomes in the encounter will be judged” (McCallum and Harrison 1985, p. 41). Hence, scripts have been related to the development of customer expectations, which impact customer satisfaction or dissatisfaction when compared with perceptions (McCallum and Harrison 1985, Smith and Houston 1983, Solomon et al. 1985). Bitner et al. (1994) also used role and script theory to examine the dynamics of the service encounter and suggested that customers and employees in strongly scripted environments will have similar expectations and perceptions about the service interaction.

To summarize, script theory has been applied in the literature to understand the roles of the customer and employee within the encounter and the evaluation of the service by all participants. We have discussed script theory to provide a conceptual framing for service scripting. To further our scripting overview, we next describe another stream of research that is pertinent to scripts, namely, organizational routines (Feldman and Pentland 2003, Gioia and Poole 1984, Leidner 1993, 1999).

\subsection{Organizational Routines}

Organizational routines as summarized by Feldman and Pentland (2003) are, “a repetitive, recognizable pattern of interdependent actions, involving multiple actors,” (p. 96) and may be formally documented through procedures or rules. Research about organizational routines has been widely covered in the literature (please refer to Becker 2004 for a review of this work). One of the more current outlooks on the topic is one that incorporates the dynamic aspects of routines. From this perspective, Feldman and Pentland (2003) decompose a routine into ostensive and performative aspects. The ostensive component refers to the detail of the routine, the "what," so to speak. It may be known through standard operating procedures or may simply be considered the norm for action (Feldman and Pentland 2003). Moreover, it serves as the guide for behavior and is equivalent to the service script itself to provide the context of how to deliver service. In contrast, the performative aspect involves how the routine is actually acted out by people (Feldman and Pentland 2003). Performing the routine helps the creation and maintenance of the routine through repetition and recognition. However, performance may also result in modification of the 
routine when the individual adapts his or her response and re-creates the ostensive aspect of the routine (Feldman and Pentland 2003).

In a service operations context, a script provides the method by which work is routinized (Leidner 1993, 1999). The ostensive aspect is the service script itself whereas the performative aspect is the actual deployment of the script by front-line employees when delivering service. Variation in how employees deliver service and their choice to deviate from the script is equivalent to routine modification. Thus, the routine's ostensive component is often dictated by the organization or management, while the employee implements the performance of the routine (Feldman and Pentland 2003).

Well-developed routines serve many positive functions for organizations that have operational relevance. For example, routines affect coordination and control, the economic use of cognitive resources, the level of uncertainty, and the stability and storage of knowledge for organizations (Becker 2004). To relate this to services, routines offer managerial control over the employee's service delivery to assure at least a minimum and uniform level of service by all employees, allow for tasks to be separated into their most efficient form, and reduce the variability between experiences (Leidner 1993). Scripts also can house knowledge and capabilities for the service firm depending on the specific type of process used. For example, a process designed for higher volume (scale) may require routines that build on the capabilities of faster processing speed whereas a process designed for higher variety (scope) may need flexibility as its capability. Within the strategic operations management literature the issue of trade-offs within process types, operational capabilities and performance has been studied widely (e.g., Boyer and Lewis 2002). Routines have been linked to the development of such operational capabilities. As a result, routines can influence operational performance and can act as a source of competitive advantage (Peng et al. 2008).

Although there is a functional side to routines, there are also potential issues that can arise (Ashforth and Fried 1988). One such issue is when employees mindlessly follow the operating routine without being cognitively present. Results of such mindless behavior include a lack of authenticity and disregard for important environmental or customer cues (Ashforth and Fried 1988). In addition, rigidly defined scripting procedures, akin to operating routines, have been tied in the literature to the emotional 
labor of service positions (Ashforth and Fried 1988, Groth et al. 2006, Leidner 1999). Emotional labor is the expectation that employees will display or conceal particular emotions to customers (Hochschild 1979). It can involve the display of genuine emotions or involve the display of emotion through surface vs. deep acting approaches for service delivery (Ashforth and Humphrey 1993). Surface acting involves employees modifying emotional displays without internally adapting their feelings, as compared with a deep acting approach where the employees attempt to modify their inner feelings to match their outward emotional display (Grandey 2003, Groth et al. 2009). It has been conceptually proposed that the decision to script has an influence on which emotional labor strategy an employee chooses (Groth et al. 2006). When rigidly scripted, employees likely rely more on surface acting, as they are unable to react spontaneously (Groth et al. 2006). In general, deep acting has been found to result in more positive outcomes for customer evaluations of the experience (Groth et al. 2009, Hennig-Thurau et al. 2006). In addition, surface vs. deep acting, has been associated with inauthenticity vs. authenticity (Grandey et al. 2005, Hennig-Thurau et al. 2006). Overall, the reviewed literature has shown both positive and negative impacts of routinized or scripted work. We now move our discussion to a particular form of routinization, a service script.

\subsection{Service Scripts}

As mentioned earlier, a service script defines the employee’s job and specifies how tasks will be completed and what outcomes should occur (Tansik and Smith 1991); it also may include specific detail for the verbal makeup of the encounter. An example of such verbal specifications is Ritz Carlton's previous use of the "20 basic rules" for service. Verbal rules for speaking to guests included using words and phrases such as “Good Morning,” “Certainly,” "I’ll be happy to,” and “My pleasure,” rather than

words such as “O.K.,” “Sure,” “Hi/Hello,” “Folks,” and “No problem.” (Sanders 2006). Studies of service scripting have tended to focus more on the sequence of events and recognized patterns of behavior rather than on the actual verbal content exchanged during the encounter (Schau et al. 2007). In addition, it appears that scripting through a script-theory lens in service research is more commonly described as a 
cognitive schema that is internally developed through experience and repetition rather than a protocol designed by the service organization. Our research interest is to examine the latter case, where verbal content is disseminated by the employee to the customer as dictated by an organizationally defined service script.

To date, the academic research regarding service scripts appears to be more conceptual than empirical (Groth et al. 2006, Tansik and Smith 1991). To our knowledge, there is a lack of work that directly measures customer perceptions of quality. However, an article by Schau et al. (2007) has empirically examined how particular types of script deviation affect several service outcomes including duration, the presence of positive or negative comments/gestures by customers, and post-service inquiries. Their observational study examined the verbal dialog between service script participants by assessing forms of ad-libbing (i.e., deviations from the script) such as switches in language, dialect, or brand codes. In addition, Victorino and Bolinger (2012) completed a content analysis of the general perceptions that customers have of script use. They found that customers primarily associate service scripting to either task or treatment-related outcomes. Customers who associated scripting with task implications viewed script use more positively than those who focused on how customer treatment was affected.

Our work adds to this growing area of research by examining verbal scripting in a more controlled environment using a video experiment. By intentionally designing different levels of scripting and attempting to keep other extraneous factors constant, we directly linked variations in script level with changes in perceived quality by customers. At the same time, we tested forms of verbal scripting under different service process contexts, namely, standardized and customized.

The application of service scripts may on the surface appear directly related to the design and management of standardized processes. However, it is not necessarily the case that all standardized encounters are highly scripted. From the provider's perspective, they want to design and deliver an apt quality offering based on their understanding of customer demands that have the potential to satisfy (Cho and Menor 2010, Roth and Menor 2003). The service process type (standardized vs. customized in this case) is a design choice that is based on customer demands and expectations and the relative need for 
economies of scale or scope. For example, when customers for the most part have homogeneous demands and similar expectations for service, the process is designed to be standardized. The script level, on the other hand, is a delivery preference based on how managers choose to deliver service to best meet the demands and expectations of the process at hand. This “customer-based” process design choice (e.g., standardized vs. customized) and the subsequent "provider-based" verbal scripting strategy preference (e.g., predominant, moderate, or relaxed script intensity) represent the "voice of the customer" and "voice of the provider” considerations that are critical in achieving the service-provider mandate proposed by Cho and Menor (2010).

The difference between process type and script intensity can also be seen in practice. For example, the check-in process at hotels is typically thought of as a standardized process which can be highly scripted for most hotels but it is not necessarily the case for all. For instance, the Ritz Carlton moved away from highly scripted encounters to interactions where employees anticipate customer needs and have the ability to adapt to different customer demands (Sanders 2006). The encounter itself may still be standardized because the same fixed sequence of steps is followed to check-in hotel guests, but the manner and verbal makeup in which it is delivered allows room for each employee to have discretion in their verbal exchange. Therefore, verbal scripting can take different forms and it is plausible to use more relaxed forms in more standardized contexts just as it is possible to use stricter forms in more customized contexts. Next, we describe the different demands of particular service processes.

\subsection{Service Process Type}

To understand service scripting we must also consider what is being scripted, namely, the service encounter. The service encounter is the “...period of time during which a consumer directly interacts with a service” (Shostack 1985, p. 243). It is within the context of the service encounter that we test how

perceived service quality is impacted by different approaches to service delivery. To do so fully, however, we must consider the type of encounter that is being experienced based on its process characteristics. 
A multitude of studies have developed categorization schemes for services based on their process characteristics (refer to Cook et al. 1999 for a review of past typology work), which in turn can be related to defining service encounter types. One of the primary considerations regarding process choice resides in the goal to achieve either higher scale (volume) or scope (variety) or some combination thereof. For example, the classic “product-process matrix” proposed by Hayes and Wheelwright (1984) provides a simple yet quite comprehensive description of the two extreme types of processes based on volume or variety. In a similar manner, Schmenner’s (1986) “service process matrix” shows how the degree of customer involvement and labor intensity within process types provide different volume and variety and require different operational capabilities. A more systematic review of service process design literature is provided below.

A traditional approach to classify services is by process- standardization level, ranging from standard to custom service (Dilworth 1986). A standardized service is defined as a process that has little variation, with process steps following a particular order and outcomes that remain fairly consistent across customers (Shostack 1987). In general, service dimensions such as consistency, efficiency, and cost become important and can be achieved within standardized services (Lovelock 1983). Alternatively, a customized service requires some flexibility so that the process can be tailored to individual customer needs (Shostack 1987). For customized services, the service outcome is likely to be uncertain (Lovelock 1983), with importance placed on personal treatment and meeting customer demands (Bowen 1990).

Similar to standardization level, previous research has also used the degree of customization as a dimension to categorize services (Bowen 1990, Haywood-Farmer 1988, Kellogg and Nie 1995, Lovelock 1983, Schmenner 1986, Silvestro et al. 1992, Wemmerlov 1990). In particular, Bowen (1990) empirically derived a classification system that was based on customer perceptions of services which included customization level. The understanding of customer perceptions helped the researchers to know what design issues were important for particular service types (Bowen 1990). For example, what became important in the standardized service segment was having well-trained and efficient service personnel whose skill could be replaced by automation or other systems. Within the customized segment, however, 
the importance was placed on personalized service that allowed customers to provide inputs to the process (Bowen 1990).

In our study, we build on the classification-of-services literature to understand the role of scripting within particular service encounter types. We leverage the knowledge of process characteristics to make predictions of what scripting strategy best fits the process type to enhance customer perceptions of quality.

\subsection{Conceptual Framework}

Tansik and Smith (1991) have proposed that scripting can be an effective way to influence employee performance. From an operations perspective, it has implications for quality assurance and can “fail-safe” service delivery (Chase and Stewart 1994, Stewart 2003). In addition, the routine literature has cited the positive influences a well-developed routine can have on important service dimensions such as reducing the level of uncertainty and cognitive efficiency (Becker 2004, Feldman and Pentland 2003). Moreover, well-defined routines aid the development of operational capabilities and impacts operational performance (Peng et al. 2008). To use scripting optimally, however, Tansik and Smith (1991) also suggest that one must consider the type of service encounter, be it one with high or low levels of customer-induced uncertainty; in other words, one that has more or fewer customization requirements.

Our study examines how an internal tool such as verbal scripting, which has operational implications for service delivery, impacts the external view of customers. We have purposefully chosen to focus this initial study of service scripting on the verbal rather than the task requirements because we believe the impact that verbal scripting has on customer perceptions is more difficult to predict. Based on role and script theory, customers have a good idea of what steps must take place to complete the service for standardized and customized encounters. Given that customers are typically familiar with the common tasks and their sequence of completion, we think it would be easier to predict how customers perceive procedural or task forms of scripting in comparison to their reaction to the behavior and language of the service provider. The influence such verbal and behavioral differences have on forming customer 
perceptions during the enactment of well-defined service process steps is what is more uncertain and should be examined.

To achieve our goals, we extend Tansik and Smith’s (1991) conceptual model to explore customer perceptions of quality based on the verbal script level chosen by the organization given a particular service context. Recall that in our study, script level refers to the degree to which the employee's verbal dialog and behavior are dictated by the service organization. For example, a service script may vary based on dimensions such as complexity level, the number of scripts, the percentage of time in scripts, or how strictly the employee is expected to follow a script (Tansik and Smith 1991). Our study explores the latter dimension, which is similar to Tansik and Smith’s (1991) notion of script intensity. On one extreme is the predominant form of scripting where little or no room is allowed for variation from the script. On the other extreme is the relaxed form of scripting, which allows the employee to deviate from the script and improvise the encounter as he or she sees fit (Tansik and Smith 1991). Hence, we sought to design encounters that pulled from these extreme cases. We also have included a moderate form of scripting to get a broader representation of script intensity.

To understand the impact that different scripting approaches have on customer perceptions of quality further, we also sought to determine if there were differences when the script was used in a particular service process type. In specific, we were interested in understanding the use of service scripts in standardized vs. customized encounters. Recall that Tansik and Smith (1991) proposed that as the level of uncertainty or room for customization increases, lower levels of scripting should be used to support the employee's ability to meet customer demands. The service-provider mandate (Cho and Menor 2010) also suggests that process type, which is determined to accommodate particular customer demands, should be a factor in the service provider's decision for what script level to use. We therefore examined the use of scripting within two service encounter types, standardized and customized.

In summary, service managers have the ability to choose different levels of scripting given the characteristics of the process at hand. To select the optimal level of scripting, we posit that one must recognize the process condition under which the service script is being used. We propose that the script 
level selected by the service organization, given the particular service process types, will have an effect on the perceived service quality by the customer. In the next section we describe specific hypotheses to formalize our conceptual proposal.

\subsection{Hypotheses}

To support the development of our hypotheses, we build from the script and routine literature to make propositions regarding the impact of scripts on customer perceptions of service quality. Furthermore, to strengthen the link between scripting and service quality perceptions, we incorporate the effect of scripting on the employee's ability to deliver service in standardized vs. customized service environments.

We begin by developing hypotheses for script use within standardized encounters. Standardized encounters, as we have reviewed, are defined by routine steps, repetitive patterns, and consistent outcomes (Shostack 1987). We posit that the nature of standardized service encounters lend themselves well to scripting techniques. The script in this case is an advantageous tool to aid the employee to deliver service and meet the demands of consistency. We propose that the overall impact of the script in a standardized environment will result in a positive assessment of the service experience by customers (i.e., higher service quality). This is in line with Tansik and Smith’s (1991) proposition that the right form of script level for a low uncertainty service context is one where the employee is expected to adhere to a script. Therefore, we propose that a completely relaxed form of scripting (the lowest script intensity for our study) will not match the process requirements, thereby hindering the employee's ability to deliver a standardized service and impacting customer perception of quality for the experience.

Where we deviate from Tansik and Smith’s (1991) model is that we believe that a script that is followed too strictly within standardized encounters will end up binding employees' discretion and limit their ability to best serve customers. A predominantly scripted encounter will likely result in more mindless behavior by the employee as they are repetitiously following the same script (Ashforth and Fried 1988) and cause service quality to suffer. Furthermore, the more rigid approach to scripting will likely 
evoke a surface acting response to service delivery (Groth et al. 2006). Deep acting has been empirically shown to be more positively viewed by customers than surface acting (Groth et al. 2009). In particular, surface acting has been associated with customers viewing the service experience as inauthentic (Grandey et al. 2005, Hennig-Thurau et al. 2006). Given that customers clearly prefer an authentic service experience (Gilmore and Pine 2007), we hypothesize that a predominantly scripted encounter does not support the highest service performance by employees. Therefore, it will not provide the highest perception of quality among the scripting options, even though the routinization of work offers many positive operational benefits that may match the requirements of a standardized encounter.

In contrast, we contend that a moderately scripted environment (i.e., allowing room for some deviation and flexibility from the designated script) will provide the highest level of perceived service quality for standardized encounters. The moderate form will still allow the formation of a routine and will provide room for efficiency and control for variability, but will also provide employees enough autonomy in their positions to change their service delivery or select words and phrases that they deem as appropriate. This idea of going off script, so to speak, refers back to the ostensive vs. performative aspect of routines (Feldman and Pentland 2003).

A more moderate form of scripting will discourage an overreliance on the script, the possibility for mindless behavior by employees, and inauthentic service delivery. A more flexible form of scripting will also allow employees to respond and adapt to customer needs with some spontaneity and will likely result in the use of deep acting strategies by the employee (Groth et al. 2006). However, the script will still be there to provide guidance and act as poka-yoke for the treatment of customers (Stewart 2003). We believe the optimal service configuration for scripting standardized encounters requires routinization of the verbal dialog to some degree but also should give employees room to deviate from the script. We therefore posit that a moderate use of scripting will result in the highest perceived service quality by customers within standardized encounters. To summarize, we propose the following hypotheses:

H1: Within a standardized service encounter, customers perceive a predominantly scripted approach to have a higher service quality than a relaxed approach to scripting. 
H2: Within a standardized service encounter, customers perceive a moderately scripted approach to have a higher service quality than a relaxed approach to scripting.

H3: Within a standardized service encounter, customers perceive a moderately scripted approach to have a higher service quality than a predominantly scripted approach.

Alternatively, customized encounters require the ability to tailor service to different customer demands and requests. Tansik and Smith (1991) proposed that the effective service design approach for more customized processes requires the intensity of the script to be low. For this case, employees may need to improvise and change how they deliver service based on customer inputs (Tansik and Smith 1991). Furthermore, too rigid an approach to scripting, as highlighted within the standardized hypotheses, has been associated with negative service delivery outcomes. For example, a mindlessly followed script may cause the employee to ignore the greater variation in customer demands or other customer signals (Ashforth and Fried 1988), which would not go unnoticed with a more relaxed approach to designing the encounter. Essentially, an obvious dilemma arises between providing a consistent service via a script that is also truly customized. Thus, we propose that the predominant use of scripting will not result in the highest level of service quality for customized encounters due to the challenge that arises for employees when attempting to provide a customized encounter that is scripted.

The optimal approach to service design in a customized service process, we predict, will be a more relaxed form of scripting. In particular, we predict that as the level of script intensity increases, the perception of service quality will be negatively affected due to the employee's inability to provide a truly tailored service. Please note, however, that while it is considered a relaxed approach, the employee would still be trained with service values and would understand the process steps required to make the service complete. In other words, the service organization would not discontinue the use of scripts entirely, but instead the employees would be given discretion over their use of the script. From a routine perspective, it 
is the performance, rather than the ostensive script, that management will have to relinquish some control over and provide employees with the power to modify the routine when necessary so employees have room to adapt their service delivery to customer needs. Hence, we propose the following hypotheses in the context of customized service encounters:

H4: Within a customized service encounter, customers perceive a relaxed approach to scripting to have a higher service quality than a predominantly scripted approach.

H5: Within a customized service encounter, customers perceive a relaxed approach to scripting to have a higher service quality than a moderately scripted approach.

H6: Within a customized service encounter, customers perceive a moderately scripted approach to have a higher service quality than a predominantly scripted approach.

\section{Research Approach}

In this section, we describe our research approach, including the study context and the video experimental design, and discuss how potential confounds were avoided. We also note the data collection process and dependent variable measurement and review the manipulation checks for our independent variables.

\subsection{Study Context}

Prior to describing the development of the video experiment, we first define the study context.

From our qualitative and secondary research we found that scripts are used in a variety of service settings from face-to-face to technology-mediated encounters and across different industries. For this initial study, however, we have chosen to focus our research and examine only face-to-face hospitality encounters. In particular, we examine two common hotel encounters, namely, the check-in process (i.e., representing a standardized encounter) and a concierge request (i.e., representing a customized encounter). The check-in 
process experimental scenario involved a customer who needs to check into her hotel room and the final outcome is the delivery of the room key. The scenario for the concierge request involves a customer who is asking for dinner recommendations where the final outcome is dining recommendations.

We have chosen the hotel context for the following reasons. First, due to the sheer size of the hotel industry there was a high probability that many potential study participants would have recent experience as hotel customers. Therefore this context allowed us to test the central proposition of the study with relative ease. Second, during the qualitative research phase we found that hospitality companies often use various forms of service scripting at different levels for training frontline employees. Therefore, we are able to use many realistic scripting techniques within the experimental design. Third, a typical hotel experience for a customer is made up of a number of different processes, some of which are standardized and others that are customized. Hence the hotel setting allowed us to retain the same general context while examining different encounter process types, using various degrees of scripting to deliver service.

\subsection{Video Experiment Design and Development}

A few studies in service operations have used video to explore the complexities of human interactions and perceptions of services (e.g., Kellogg and Chase 1995, Seawright and Sampson 2007). These works have led to important contributions to the literature, which include gaining insights about customer contact (Kellogg and Chase 1995) and wait line management (Seawright and Sampson 2007). Other researchers within the broader service field have also employed video to investigate the subjective aspects of services (e.g., Dallimore et al. 2007, Luong 2005, Mattila et al. 2003, McColl-Kennedy et al. 2003)

We believed that a video experiment realistically addressed the exploration of our research questions because video allowed us to capture the intangible aspects to the service encounter, namely, the experience itself, better than a written scenario experiment. Furthermore, a video experiment allowed us to have more control over the independent variables than a field experiment, hence assuring higher internal validity. Furthermore, Bateson and Hui (1992) found that video experiments reflect similar 
psychological and behavioral responses as real service settings. Although video has been used more frequently in the broader services domain, it is still a newer approach for operations management; therefore we describe the design of the video experiment below.

The video experiment was designed by the principal investigator, and actors were hired to emulate the written service scenarios. To develop the video experiments, a number of steps were followed and the main phases of our research are outlined in Figure 1. First, we began with a qualitative analysis. Seventeen interviews were conducted with a mix between managers and employees. The interviews consisted of questions about service delivery and different approaches toward standardized vs. customized interactions, and ended with a discussion of script usage in practice. The qualitative extrapolations made within this research phase helped provide the research team with an understanding of the current use of service scripts that was grounded in practical relevance. In addition, the interviews provided the research team with anecdotal examples of service script rules, supported the development of our conceptual model, and were also leveraged to design the experimental scenarios.

Next, we developed the experimental service scenarios. We conducted a series of pilot studies to refine the written drafts used by the actors in preparation for the filming of the service vignettes. Each written scenario contained three basic steps: begin with a greeting, deliver the desired service outcome, and close the encounter. Examples of the service script rules for the standardized case were to call all guests "sir" or "miss" or formally address them by their last name, greet the customer with "good morning, afternoon or evening,” then welcome the guest with the hotel name and motto, advise the customer about the promotional upgrade option based on a scripted guideline, follow the hotel brochure for describing the hotel layout and amenities and in closing wish the customer a quality experience, thank the customer for their business, and let the customer know where they can find assistance should they need help while staying at the hotel. For the customized encounter, examples of the service script rules again involved calling all guests "sir” or "miss” or formally address them by their last name, asking the guest if you may be of assistance, following a designated description of the highly recommended hotel restaurant, encouraging the customers to try the hotel's restaurant during their stay at the hotel, providing 
set recommendations for other restaurants based on a hotel map, and closing by complementing the customer on their dinner choice and letting the guest know it was a pleasure to help them.

The intention in the experimental design was to manipulate only the verbal script level used by the actor who was playing the role of the employee, under either a standardized or customized encounter. Therefore, when creating the vignettes for the different levels of scripting, we assured that the number and sequence of tasks to be completed remained constant; the only thing that changed was the language used. Our piloting phase for the written scenarios provided us with information regarding our service script manipulation in the design of the encounter. We went through multiple iterations of revising the written scenarios to assure the best reflection of script usage in a hotel setting. In particular, the main issue raised within our piloting work was determining how to best depict the moderate use of scripting. After two rounds of piloting with college students were completed, we found empirical support for the manipulations used in the written experimental scenarios.

Next, we finalized the specifics for the video experiment. Two actors, one to play the role of the employee and the other to play the role of the customer, were hired. A film crew with knowledge of lighting, filming, and editing was also hired, and approval to film at a hotel venue was received. During the video shoot, an attempt was made to create an encounter that was realistic. Thus the actor playing the part of the employee was not expected to follow the written scenarios to the letter, as it is hard to imagine a face-to-face encounter where an employee would literally be reading from a script. Thus, the actor was allowed multiple takes for each encounter with the version selected that resembled the intended design best. The manipulation was the intensity of verbal scripting used by the actor who portrayed the employee role. For the predominantly scripted case the actor was expected to follow the service script rigidly by abiding by the script rules described above. More flexibility and room for ad-libbing with regard to the choice of words was allotted to reflect the moderately scripted interaction. In addition, the lowest script intensity scenario was created by allowing the actor to improvise on the day of the shoot. That is, the actor was allowed to choose her own words and phrases and did not have to follow the verbal script rules. Although the employee's role was varied across the takes, the customer's role was kept consistent. Thus, 
the customer had the same responses for each scenario. The coordination of receiving venue permission as well as actor and film crew scheduling and expense associated with filming limited us in our ability to pilot the video scenarios. Due to this limitation we went through multiple phases of piloting the written scenarios prior to filming to support the developed video scenarios.

The end product was video clips of service encounters where the level of service script varied. The experiment consisted of a 2 x 3 between-groups design. The independent variables of interest were the service encounter type and script level. The service encounter type was either (i) standardized checkin encounter or (ii) customized concierge encounter. Script level was (i) predominantly scripted, (ii) moderately scripted, or (iii) relaxed. Initially, the design included four script levels. However, the pairwise analysis of the middle script levels for script perception was not found to be statistically different and thus were collapsed into one level and labeled as moderately scripted. An overview of the conditions for the six experimental scenarios is provided in Table 1.

\subsection{Mitigation of Potential Confounds}

Because the video scenarios used within the experiment were designed by the research team, we were able to keep many of the other variables related to the service encounter that may also influence perceived service quality consistent and thus limit the potential for confounds. First, for the employee and customer role we used the same professional actresses across vignettes. In all cases, the employee was wearing the same attire and had similar facial expressions. Furthermore, the content delivered by the employee was kept consistent across the vignettes. For example, if the employee offered a sales promotion in one scenario she would also have to do so in the other scenarios. In addition, each of the encounters had three phases: a greeting, the delivery of the required service, followed by a closing to the interaction. Therefore, the task complexity, including the sequence of processing tasks, was fixed for both encounter types. The outcome was also the same across all encounters: for the check-in encounter the customer was given keys to her hotel room, while for the customized encounter the customer was provided dinner recommendations. Given that the content and service outcome were kept consistent, we 
assumed that inferences regarding training or experience level would be similar. The emotional display by the employee was comparable across scenarios (i.e., her demeanor was pleasant, which is in line with typical expectations of hotel staff). Finally, the customer response was verbatim in all cases and her face was not shown to deter any biases introduced from facial suggestions. Thus, the customer's role was kept as consistent as possible across encounters.

After filming the video scenarios, the clips were inserted into an online questionnaire. The next section describes the data collection procedure, dependent variable measurement, and manipulation checks of the independent variables (i.e., service process type and script level).

\subsection{Data Collection and Sample}

To capture a dataset that represented a national sample of individuals from the United States population who had recent experience as hotel guests, a reputable market research company was hired. With a goal of receiving close to 1000 completed responses, the sampling company sent invitations to randomly selected individuals in batches of 1000 every few days until the desired quota was reached. The survey was closed after slightly over 900 responses were received within approximately a week. Of the responses, 700 individuals met the screening criteria of staying in a hotel during the last year. We then removed respondents who took less than 10 minutes to complete the survey due to the length of the survey. The majority of these survey responses had more than half of the responses unanswered.

Respondents were randomly assigned to watch one of the video scenarios and then were asked questions pertaining to their perception of service quality. The video scenario clips were roughly 2 minutes in length and within an approximate range of 30 seconds. Random assignment was used to alleviate the potential for extraneous variables such as personal factors to affect the outcome of the study (Seawright and Sampson 2007). Some respondents did not answer any of the service quality items and thus were deleted from the dataset for the video experiment analysis. Other respondents missed or selected “I don't know” for one or more of the items. Rather than treat these responses as missing from the system, the missing response was substituted with the series mean for that item (Tsikriktsis 2005). 
After attributing for missing responses, the median time respondents took to complete the survey was between 17 and 18 minutes and a sample of 465 was obtained with more than 45 individuals assigned to each experimental group as shown in Table 2.

The retained sample included a mixture of demographic types. Of the respondents, approximately $20 \%$ were 40 years old or younger and 56\% between 41 and 60 years old. The majority of the respondents were women, with about a third being men. Respondents had various levels of education and income. The majority of respondents ranged from college to graduate degrees for education levels and almost half had an income between $\$ 50,001$ and $\$ 125,000$. The respondents were well representative of a variety of traveler types.

\subsection{Dependent Variable Measurement}

The dependent variable was represented by a measure for customer perceived service quality. This was estimated using SERVPERF (Cronin and Taylor 1992), a 22-item service quality scale based on the perception items of SERVQUAL (Parasuraman et al. 1988) to estimate customer perceptions of service quality. The SERVPERF items were only slightly edited by including the fictitious hotel name and making minor readability changes. The main content of the items was retained. SERVPERF has been validated and found to be a good measure for service quality (Brady et al. 2002).

Service quality is defined by five dimensions: reliability, responsiveness, assurance, empathy, and tangible evidence (Parasuraman et al. 1988). The items measured are related to one of these five dimensions and are composited to assess customer perceptions of quality. We consciously chose to utilize the full 22-item scale to determine a customer's overall perception of quality. We did not want to remove dimensions because we would not be able to get an overall reflection of the experience which included all five dimensions for the video experiment. The 22-item SERVPERF scale used within our study was tested for reliability, and the Cronbach's alpha was above the traditional cut-off level. Therefore, the dependent variable of customer perceived quality was based on the composite score of the 22-item SERVPERF scale. 


\subsection{Independent Variable Manipulation Check}

To test that the respondents were able to perceive the different independent variable levels, we empirically validated the experimental manipulations. First, we assessed the independent variable of service encounter type. Recall that the experiment portrayed two levels of standardization, one (i.e., hotel check-in) being more standardized and the other (i.e., concierge service) more customized. We asked respondents the following question after the video clip: “How standardized (meaning the service interaction involves routine and structured steps; provision of the same service to all customers) was the service interaction?” Respondents answered on a 1-7 Likert scale with 7 representing a very standardized interaction. Scenarios across all standardized encounters were collapsed into one group and scenarios for all customized encounters into another group to compare if respondents were able to distinguish different standardization levels across the two encounter types. The service encounter process type was detected by respondents $(\mathrm{F}(1,463)=9.205, \mathrm{p}<0.01)$. Respondents viewed the standardized encounter $(M=5.52$, SD $=1.19$ ) to be more standardized in comparison with the customized encounter $(M=5.14, \mathrm{SD}=1.45)$.

Although the difference for the mean perceived standardization level was significant, both the standardized and customized encounters had mean scores greater than 5 . The higher rating for the standardization level of the customized encounter is likely due to the fact that the concierge interaction was a fairly routine request from customers (i.e., dinner recommendations). We purposefully selected a more familiar type of customized encounter so that respondents could easily relate to the encounter they witnessed. Nevertheless, the employee still had to tailor the response, as she is more likely to see heterogeneity in customer requests in comparison with the standardized encounter. As a result, we do find that the differences between the perceptions of standardization level across the encounter types were significant.

Next, we examined if respondents were able to detect the different service script levels used to design the service encounters. We investigated perception of script level by consolidating the scripting levels across both encounter types. Utilizing a composite service script measure on a 1 to 7 scale where 7 represents a highly scripted interaction, we assessed if respondents perceived the use of verbal scripting. 
The main effect for service script level detection was significant $(F(2,462)=17.791, \mathrm{p}<0.001)$.

Respondents perceived three distinct service script levels with the predominantly scripted case $(M=5.17$, $\mathrm{SD}=1.14)$ being recognized as the most scripted in comparison with the moderately scripted case $(M=$ $4.75, \mathrm{SD}=1.09)$ and the relaxation of script case $(M=4.31, \mathrm{SD}=1.21)$ perceived as the least scripted. Please refer to Victorino et al. (2012) for a complete review of the empirical support that was found for customer detection of script level and the insights this finding has for service design.

\section{Analysis and Results}

We now present and discuss the results of our experiment. We adopted a two-step approach to analyze the results. First, we analyzed the 2 (service process type: standardized vs. customized) 93 (script level: predominantly scripted, moderately scripted, and relaxed form of scripting) between-subjects design and then we looked more carefully at the interaction between the factors. The main effects for script level $(\mathrm{F}(2,459)=1.037, \mathrm{p}>0.05)$ and process type $(\mathrm{F}(1,459)=2.08, \mathrm{p}>0.05)$ were both nonsignificant. The quality perceived by respondents was thus not affected by either script intensity level or process type independently. The interaction effect between process type and script level, on the other hand, was significant $(\mathrm{F}(2,459)=3.145, \mathrm{p}<0.05)$. The significant interaction implies that the perceived quality by respondents for a particular script intensity depended upon the process type of the service encounter.

To interpret the interaction effect and formally test the proposed hypotheses, we then segregated the data by process type (standardized vs. customized) and assessed differences in perceived quality across the designed script levels. Two 1 (either standardized or customized) x 3 (script level:

predominantly scripted, moderately scripted, and relaxed form of scripting) between-group ANOVA tests were analyzed. Beginning with the analysis of the standardized service encounter data, no support was found for hypotheses 1,2 , or $3,(F(2,237)=0.342$, $p>0.05)$. Consequently, all pairwise comparisons across script intensity levels were not significant. Although a statistically significant difference was not detected across the script intensity levels, the perceived quality of the predominantly scripted approach 
$(M=5.85, \mathrm{SD}=0.84)$ was viewed as being slightly higher than the moderately scripted $(M=5.77, \mathrm{SD}=$ $0.87)$ and the relaxed approach $(M=5.74, \mathrm{SD}=0.74)$. Respondents were therefore not viewing the perceived quality to be different for the script intensity levels within the standardized encounters.

In contrast, the predicted effect was observed for customer perceptions of service quality for customized encounters $(\mathrm{F}(2,222)=3.546, \mathrm{p}<0.05)$. Pairwise comparisons by examining independent ttests between groups was conducted to examine which means were different between the three script intensity levels. Supporting hypothesis 4, the analysis revealed that respondents perceived a relaxed approach to scripting $(\mathrm{M}=5.80, \mathrm{SD}=0.92)$ to be of higher quality than a predominantly scripted approach $(\mathrm{M}=5.42, \mathrm{SD}=1.06, \mathrm{t}(115)=2.007, \mathrm{p}<0.05)$. As predicted, the analysis also indicated that respondents perceived a moderately scripted approach $(\mathrm{M}=5.76, \mathrm{SD}=0.82)$ to be of higher quality than a predominantly scripted approach $(\mathrm{M}=5.42, \mathrm{SD}=1.06, \mathrm{t}(121)=2.269, \mathrm{p}<0.05)$. Therefore, hypothesis 6 was also supported. However, no support was determined for hypothesis 5, as respondents perceived no difference in quality between the customized encounters that used a relaxed form of scripting compared with those that used a moderate approach $(\mathrm{t}(153)<1)$.

In addition to examining the effects that verbal script level has on customer perceptions of service quality, we also assessed if there were differences in perceptions of quality as a function of a customer's background. Table 3 lists the distribution of demographic characteristics and other customer-background variables for each of the experimental script levels. To explore the potential relationships between customer descriptors (such as age) and perception of service quality, a series of ANOVA tests was completed comparing the mean score for quality perception between the sub-groups for both the standardized and customized encounters at each of the verbal script levels. We found that the majority of distinguishing factors between individuals were not associated with their perception of service quality for the three script levels. These results imply that the observed findings are primarily due to changes in verbal script level and not a result of customer-background factors. Gender, however, did have an effect on quality perception for both the relaxed and moderately scripted levels across both encounter types. In 
particular, females on average tended to view both of these levels more positively than did males. For the predominantly scripted levels, there was no effect found for any of the tested respondent characteristics.

\section{Conclusions and Implications}

Tansik and Smith (1991) conceptually proposed that service managers must choose the right form of scripting based on the encounter's characteristics because different uses of scripts can either inhibit or support service performance. Building from their conceptual model, we have found empirical evidence that suggests that service managers must also consider how scripts impact customer perceptions of quality when selecting the optimal form of scripting. Our work emphasizes the importance of understanding and measuring customer perceptions to enhance service design and being cognizant of the requirements of particular encounter types. We contribute to the service operations literature by empirically examining the optimal form of scripting the service encounter based on customer perceptions of quality for both standardized and customized encounters. Prominent service operations scholars have noted the discrepancy of academic publications regarding service process design topics which included the study of scripted dialogs (Hill et al. 2002). We believe this article makes one of the first empirical contributions for service operations regarding scripting and hope that it acts as a starting point for more research.

The results from the video experiment suggest that customers perceive the use of service scripting differently given the process type associated with the encounter. Customer perceptions of service quality were only affected if the encounter was customized rather than standardized. In particular, for customized encounters, customers viewed the predominantly scripted interaction to have the lowest service quality in comparison with less scripted interactions. However, there was no difference between customer perceptions of quality for moderate levels of scripting in comparison with a more improvised encounter. This suggests that a service organization could still reap the benefits of control and consistency within customized encounters if the script is enforced in a manner that is more flexible. Furthermore, the benefits of scripting such as managerial control, cognitive efficiency, and reduced variation (Becker 2004) 
between encounters can be gained for standardized processes without affecting customer quality perceptions.

Moreover, our work builds on the organizational routine literature by exploring the link between the ostensive and performative aspects of a particular kind of routine (i.e., a service script). The ostensive aspect of the routine was the defined service script and the performative aspect was the way that the actor delivered the routine. How the script was enacted was dependent on how much room for improvisation was allotted. Our results show that understanding the link between the ostensive and performative aspect of a script has the potential to increase customer perceptions of quality. In particular, under customized encounters a freer approach to scripting improved quality whereas a stricter adherence and structure to the routine was possible for standardized encounters without sacrificing quality. Therefore, our study highlights the distinction of the ostensive and performative aspects to scripting and illustrates when it is necessary to modify or adapt the ostensive routine given the service process type. Furthermore, our findings support that the proper alignment of routines to process requirements can help develop an operational capability, thereby adding further support to the work of Peng et al. (2008), who found that well-developed routines enhance operational capability. Our research adds to the service operations literature in the following ways. First, it provides further weight to the importance of incorporating the customer's view to service design decisions, as Chase and Dasu (2001) have also promoted. In light of the many operational advantages (e.g., efficiencies and uncertainty reduction that can be gained from scripting techniques), one must also consider the impact scripts have on the customer experience. Second, we find that there are indeed boundary conditions for the optimal use of scripting. Tansik and Smith (1991) showed the impact scripts have on employee performance and we have used their framework to begin to understand the customer's view. Our work proposes that the decision to script should not be made lightly. Service managers must consider the type of encounter and match it with the right form of scripting when designing the encounter to assure a positive customer experience. As an aside, we have also tested a section of Tansik and Smith's (1991) conceptual model but from the customer's perspective of the encounter. We find support for their proposition related to script intensity level for high customer 
uncertainty environments. Specifically, a lesser script intensity is appropriate for high variability demand systems based on customers' perceptions of the encounter. Third, our work has attempted to satisfy the conflicting objectives of the service encounter parties (i.e., service organization, employee, and customer) (Bateson 1985). By being creative and using different forms of scripting, services can balance the organization's need for operational efficiency and consistency with the employee’s need for autonomy and the customer’s desire to be satisfied (Bateson 1985). From a more general service perspective, this work sheds light on developing a service concept that aligns the operational considerations, or the "how" of service, with customer needs, or the "what" of service (Goldstein et al. 2002). It also sheds light on the design and delivery of a suitable level of quality by linking service-provider design considerations to the “voice of the customer.” (Cho and Menor 2010, Roth and Menor 2003). Our finding pertaining to the moderate form of scripting being a positively viewed experience by customers suggests that service firms can still benefit from efficient, low cost, and complete service without negatively impacting the customer experience. For standardized encounters, various forms of scripting could be used without influencing service quality. Overall, incorporating the customer’s view into service design strategy will help organizations determine when it is best to use scripting and in which form, to deliver experiences which customers value.

Perhaps our most significant contribution is the implications that this work provides to service managers who oversee the service design process or train front-line employees. These insights can be leveraged to support service design so that standards for service are developed that incorporate customer perceptions given the service process at hand. Managers can develop customer-defined standards that take into consideration what the customer views as a high quality experience rather than focusing only on company-defined standards such as productivity or efficiency (Zeithaml et al. 2007). The scripting strategy used is one way that the actions of the employee are prescribed to reflect the desired standard for service. Our study suggests that service managers consider not only the internal operational benefits that scripting may provide but also think about how customers will perceive the service level. They can thereby assure that the standards developed for service (e.g., how scripted the encounter should be) and 
how these standards are evaluated (e.g., how strictly employees are expected to adhere to the script) are in line with customer expectations of a quality service.

We also think it is imperative for managers to consider carefully the process type along with the customer’s perspective prior to their decision to script. Essentially, the more knowledge and understanding management has about customer perceptions of the service delivered, the more the gap between manager perceptions of customer expectations will be reduced (Ziethaml et al. 1988). In addition, our intention is that insights from this scripting study will be incorporated into service design efforts. For example, managers can include the consideration of scripting form within service blueprints to focus training and labor efforts as well as resource deployment to enhance the customer experience. We also envision that the type of video analysis we employed can be used in practice so that service managers can select the best design for the encounter. Managers can develop video scenarios that test different service configurations or innovations prior to full launch. Subsequently the optimally designed encounter video can be used for training purposes. Managers will be able to learn about and improve the intangible aspects of the encounter experience without having to implement and test different approaches on the actual service floor.

While the experimental study described in the article was executed within the context of the hospitality industry, the theoretical constructs such as process type (e.g., standardized vs. customized encounter or economy of scale vs. economy of scope), the level of script intensity, and the dependent variable (i.e., perceived quality) are present in many different types of face-to-face service encounters (e.g., retail, financial services, and healthcare, to name a few). Therefore, the conclusions derived can potentially be generalized to other service industries. At the same time, we do note that additional studies should be conducted in other types of service industries to confirm the results observed in our work.

Our research provides many valuable academic and managerial implications for service design. However, we realize that it is an initial study of scripting and is exploratory in nature. Thus, there are limitations to this study that we would like to pose as future areas for research. First, given our design constraints we were unable to directly measure expectations of customers. Research has illustrated that 
customer expectations are developed based on their cognitive script and are used as a basis for evaluating the encounter (McCallum and Harrison 1985, Smith and Houston 1983, Solomon et al. 1985). An empirical assessment which incorporates customer expectations will provide further insights into understanding the effect scripting has on quality.

Second, the focused approach we have taken in this initial study leaves the opportunity to examine many other variables that may affect the perception of scripting as well as other service dimensions. A logical extension of our work is to examine the complexity of scripted tasks, which was kept consistent in our experimental design, in addition to the language used in the script. For example, a 2 (task scripting vs. verbal scripting) 93 (predominantly scripted, moderately scripted, and relaxation of script) design would help to understand the relation between scripting and perceived quality further. In addition, work that empirically tests the cultural effects that are associated with scripting or other background effects such as personality type or demographic characteristics would also be of value. Work has already been done that provides the theoretical foundation to the cultural effects of scripting (Hopkins et al. 2009). Another research opportunity would be to examine other forms of scripting such as the use of simple vs. complex scripts or to examine how the number of scripts for a position affects performance. Or one might also examine other service dimensions (such as customer involvement level), other types of encounters (such as technology-mediated encounters), or other industries. Or one could study particular aspects of service performance such as the effects scripting has on efficiency, variability, or other operationally relevant measures.

Third, work which examines each dimension of quality should also be considered. For example, future work should examine effects on particular aspects of quality such as responsiveness or empathy. Finally, due to the novelty and exploratory nature of the study, empirical work that verifies or validates this work is necessary. Research that refines the video scenarios and scales or uses other measures to estimate service quality is definitely encouraged.

Fourth, scripting impacts other measures of operational performance beyond quality (e.g., speed of service; cost). However, given that this article is the first study which experimentally verifies the 
impact of scripting, we wanted to simplify and focus the experimental design to the extent possible. Therefore, we focused on one key aspect of performance (i.e., perceived quality) which in itself happens to be a multi-dimensional construct. Including other performance measures (e.g., speed of service, cost, etc.) would have required a more elaborate and complex video shoot and experimental design. We note that follow-up research should try to explicitly consider the impact of scripting on a broader set of measures for operational performance.

To conclude, scripts are an efficient job design tool that influence employee performance (Tansik and Smith 1991). It is also important, however, to understand the effect an operational policy such as scripting has on customer perceptions of service quality. Understanding the nature of the service encounter and properly matching the level of script with the service process type will aid the development of a service encounter that customers view more positively. Future research that continues to examine empirically the use of scripts for service design will help shed more light on this important service operations issue. 


\section{Acknowledgments}

The authors would like to thank the Cornell Center for Hospitality Research and the Institute for the Social Sciences at Cornell University for providing grants to support the video experiment development and data collection. 


\section{References}

Abelson, R. F. 1976. Script processing in attitude formation and decision making. J. S. Carroll, J. S. Payne, eds. Cognition and Social Behavior. Erlbaum, Hillsdale, NJ, 33-45.

Ashforth, B. E., Y. Fried. 1988. The mindlessness of organizational behaviors. Hum. Relat. 41(4): 305329.

Ashforth, B. E., R. H. Humphrey. 1993. Emotional labor in service roles: The influence of identity. Acad. Manag. Rev. 18(1): 88-115.

Bateson, J. E. G. 1985. Perceived control and the service encounter. J. A. Czepiel, M. R. Solomon, C. F. Surprenant, eds. The Service Encounter: Managing Employee/Customer Interaction in Service Businesses. Lexington Books, Lexington, MA, 67-82.

Bateson, J. E. G., M. K. Hui. 1992. Ecological validity of photographic slides and videotapes in simulating the service setting. J. Consum. Res. 19(2): 271-281.

Becker, M. C. 2004. Organizational routines: A review of the literature. Indust. Corp. Change 13(4): 643-677.

Bitner, M., B. H. Booms, L. A. Mohr. 1994. Critical service encounters: The employee’s viewpoint. J. Market. 58(4): 95-106.

Bowen, J. 1990. Development of a taxonomy of services to gain strategic marketing insights. J. Acad. Market. Sci. 18(1): 43-49.

Boyer, K. K., M. Lewis. 2002. Competitive priorities: Investigating the need for trade-offs in operations strategy. Prod. Oper. Manag. 11(1): 9-20.

Brady, M. K., J. J. Cronin, R. R. Brand. 2002. Performance-only measurement of service quality: A replication and extension. J. Bus. Res. 55(1): 17-31.

Carlzon, J. 1987. Moments of Truth. Harper and Row, New York.

Chase, R. B., S. Dasu. 2001. Want to perfect your company’s service? Use behavioral science. Harv. Bus. Rev. 79(6): 78-84.

Chase, R. B., D. M. Stewart. 1994. Make your service fail-safe. MIT Sloan Manag. Rev. 35(3): 35-44. 
Cho, Y. K., L. J. Menor. 2010. Toward a provider-based view on the design and delivery of quality eservice encounters. J. Serv. Res. 13(1): 83-95.

Cook, D. P., C. Goh, C. H. Chung. 1999. Service typologies: A state of the art survey. Prod. Oper. Manag. 8(3): 318-338.

Cronin, J. J., S. A. Taylor. 1992. Measuring service quality: A reexamination and extension. J. Market. 56(3): 55-68.

Czepiel, J. A., M. R. Solomon, C. F. Surprenant, E. G. Gutman. 1985. Service encounters: An overview. J. A. Czepiel, M. R. Solomon, C. F. Surprenant, eds. The Service Encounter: Managing Employee/Customer Interaction in Service Businesses. Lexington Books, Lexington, MA, 3-15.

Dallimore, K. S., B. A. Sparks, K. Butcher. 2007. The influence of angry customer outbursts on service providers’ facial displays and affective states. J. Serv. Res. 10(1): 78-92.

Dilworth, J. B. 1986. Production and Operations Management, 3rd edn. Random House, New York.

Feldman, M., B. Pentland. 2003. Reconceptualizing organizational routines as a source of flexibility and change. Adm. Sci. Q. 48 (1): 94-118.

Frei, F. X. 2006. Breaking the trade-off between efficiency and service. Harv. Bus. Rev. 84(11): 93-101.

Gilmore, J. H., B. J. Pine. 2007. Authenticity: What Consumers Really Want. Harvard Business School Press, Boston, MA.

Gioia, D. A., P. P. Poole. 1984. Scripts in organizational behavior. Acad. Manag. Rev. 9(3): 449-459.

Goldstein, S. M., R. Johnston, J. Duffy, J. Rao. 2002. The service concept: The missing link in service design research? J. Oper. Manag. 20(2): 121-134.

Grandey, A. 2003. When the show must go on: Surface and deep acting as predictors of emotional exhaustion and service delivery. Acad. Manag. J. 46(1): 86-96.

Grandey, A. A., G. M. Fisk, A. S. Mattila, K. J. Jansen, L. Sideman. 2005. Is “service with a smile”’ enough? Authenticity of positive displays during service encounters. Organ. Behav. Hum. Decis. Process. 96(1): 38-55. 
Groth, M., T. Hennig-Thurau, G. Walsh. 2006. A conceptual model of the effects of emotional labor strategies on customer outcomes. W. J. Zerbe, N. M. Ashkanasy, C. E. J. Hartel, eds. Individual and Organizational Perspectives on Emotion Management and Display Research on Emotion in Organizations, Vol. 2. Elsevier, Oxford, UK, 219-236.

Groth, M., T. Hennig-Thurau, G. Walsh. 2009. Customer reactions to emotional labor: The roles of employee acting strategies and customer detection accuracy. Acad. Manag. J. 52(5): 958-974.

Hayes, R. H., S. C. Wheelwright. 1984. Restoring Our Competitive Edge: Competing Through Manufacturing. John Wiley \& Sons, New York.

Haywood-Farmer, J. 1988. A conceptual model of service quality. Int. J. Oper. Prod. Manag. 8(6): 1929.

Hennig-Thurau, T., M. Groth, M. Paul, D. Gremler. 2006. Are all smiles created equal? How emotional contagion and emotional labor affect service relationships. J. Market. 70(3): 58-73.

Heskett, J. L., T. O. Jones, G. W. Loveman, W. E. Sasser, Jr., L. A. Schlesinger. 1994. Putting the service profit chain to work. Harv. Bus. Rev. 72(2): 164-170.

Hill, A. V., D. A. Collier, C. M. Froehle, J. C. Goodale, R. D. Metters, R. Verma. 2002. Research opportunities in service process design. J. Oper. Manag. 20(2): 189-202.

Hochschild, A. R. 1979. Emotion work, feeling rules, and social structure. Am. J. Sociol. 85(3): 551-575. Hopkins, S. A., W. Nie, W. E. Hopkins. 2009. Cultural effects on customer satisfaction with service encounters. Journal of Service Science 2(1): 45-56.

Kellogg, D., R. B. Chase. 1995. Constructing an empirically derived measure of customer contact. Manage. Sci. 41(11): 1734-1749.

Kellogg, D., W. Nie. 1995. A framework for strategic service management. J. Oper. Manag. 13(4): 323337.

Leidner, R. 1993. Fast Food, Fast Talk: Service Work and the Routinization of Everyday Life. University of California Press, Los Angeles, CA.

Leidner, R. 1999. Emotional labor in service work. Ann. Am. Acad. Polit. Soc. Sci. 561(1): 81-95. 
Lovelock, C. H. 1983. Classifying services to gain strategic marketing insights. J. Market. 47(3): 9-20.

Luong, A. 2005. Affective service display and customer mood. J. Serv. Res. 8(2): 117-130.

Mattila, A. S., A. A. Grandey, G. M. Fisk. 2003. The interplay of gender and affective tone in service encounter satisfaction. J. Serv. Res. 6(2): 136-143.

McCallum, J. R., W. Harrison. 1985. Interdependence in the service encounter. J. A. Czepiel, M. R. Solomon, C. F. Surprenant, eds. The Service Encounter: Managing Employee/Customer Interaction in Service Businesses. Lexington Books, Lexington, MA, 35-48.

McCarthy, I. P., L. Pitt, P. Berthon. 2010. Service customization through dramaturgy. F. S. Fogliatto, G. J. C. da Silveira, eds. Mass Customization: Engineering and Managing Global Operations. Springer-Verlag, London, 43-64.

McColl-Kennedy, J. R., C. S. Daus, B. A. Sparks. 2003. The role of gender in reactions to service failure Metters, R., A. Marucheck. 2007. Service management: Academic issues and scholarly reflections from operations management researchers. Decision Sci. 38(2): 195-214.

Parasuraman, A., V. A. Ziethaml, L. L. Berry. 1988. SERVQUAL: A multiple-item scale for measuring consumer perceptions of service quality. J. Retail. 64(1): 12-40.

Peng, D. X., R. G. Schroeder, R. Shah. 2008. Linking routines to operations capabilities: A new perspective. J. Oper. Manag. 26(6): 730-748.

Roth, A. V. 2007. Applications of empirical science in manufacturing and service operations. manufacturing and service operations management. Manufact. Serv. Oper. Manag. 9(4): 353367.

Roth, A. V., L. Menor. 2003. Insights into services research: A research agenda. Prod. Oper. Manag. 12(2): 145-164.

Sanders, P. 2006. Takin’ off the ritz—a tad: Chain relaxes service 'rules' to rely on workers’ judgment; No more escorts to the restroom. Wall St. J. June 23, p. B1.

Schau, H. J., S. Dellande, M. C. Gilly. 2007. The impact of code switching on service encounters. J. Retail. 83(1): 65-78. 
Schmenner, R. W. 1986. How can service businesses survive and prosper. Sloan Manag. Rev. 27(3): 2132.

Seawright, K. K., S. E. Sampson. 2007. A video methodology for empirically studying wait-perception bias. J. Oper. Manag. 25(5): 1055-1066.

Shostack, L. 1985. Planning the service encounter. J. A. Czepiel, M. R. Solomon, C. F. Surprenant, eds. The Service: Managing Employee/Customer Interaction in Service Businesses. Lexington Books, Lexington, MA, 243-253.

Shostack, L. 1987. Service positioning through structural change. J. Market. 51(1): 34-43.

Silvestro, R., L. Fitzgerald, R. Johnston, C. Voss. 1992. Towards a classification of service processes. Int. J. Serv. Ind. Manag. 3(3): 62-75.

Smith, R. A., M. J. Houston. 1983. Script-based evaluations of satisfaction with services. L. L. Berry, L. Shostack, G. D. Upah, eds. Emerging Perspectives in Service Marketing. American Marketing, Chicago, IL, 504-508.

Solomon, M. R., C. F. Surprenant, J. A. Czepiel, E. G. Gutman. 1985. A role theory perspective on dyadic interactions: The service encounter. J. Market. 49(1): 99-111.

Stewart, D. M. 2003. Piecing together service quality: A framework for robust service. Prod. Oper. Manag. 12(2): 246-265.

Tansik, D. A., W. L. Smith. 1991. Dimensions of job scripting in services organisations. Int. J. Serv. Ind. Manag. 2(1): 35-49.

Tsikriktsis, N. 2005. A review of techniques for treating missing data in OM survey research. J. Oper. Manag. 24(1): 53-62.

Victorino, L., A. R. Bolinger. 2012. Scripting employees: An exploratory analysis of customer perceptions. Cornell Hosp. Q. 53(3): 196-206.

Victorino, L., R. Verma, B. L. Bonner, D. G. Wardell. 2012. Can customers detect script usage in service encounters?: An experimental video analysis. J. Serv. Res. Forthcoming. Wemmerlov, U. 1990. A 
taxonomy for service processes and its implications for system design. Int. J. Serv. Ind. Manag. 1(3): 20-40.

Ziethaml, V. A., L. L. Berry, A. Parasuraman. 1988. Communication and control processes in the delivery of service quality. J. Market. 52(2): 35-48.

Zeithaml, V. A., M. J. Bitner, D. Gremler, T. Mahaffey, B. Hiltz. 2007. Services Marketing: Integrating Customer Focus Across the Firm, Canadian Edition. McGraw-Hill Ryerson, Toronto.

Zomerdijk, L. G., C. A. Voss. 2010. Service design for experience-centric services. J. Serv. Res. 13(1): 67-82. 
Table 1. Experimental design

\begin{tabular}{lll}
\hline Scenario & Verbal script intensity & Service process type \\
\hline Scenario \#1 & Relaxed script & Standardized \\
Scenario \#2 & Moderately scripted & Standardized \\
Scenario \#3 & Predominantly scripted & Standardized \\
Scenario \#4 & Relaxed script & Customized \\
Scenario \#5 & Moderately scripted & Customized \\
Scenario \#6 & Predominantly scripted & Customized \\
\hline
\end{tabular}


Table 2. Sample Size for Each Service Scenario

\begin{tabular}{lccc}
\hline & $\begin{array}{c}\text { Standardized } \\
\text { encounter }\end{array}$ & $\begin{array}{c}\text { Customized } \\
\text { encounter }\end{array}$ & Total \\
\hline Relaxation of script & 67 & 47 & 114 \\
Moderately scripted & 110 & 108 & 218 \\
Predominantly scripted & 63 & 70 & 133 \\
Total & 240 & 225 & 465 \\
\hline
\end{tabular}


Table 3. Distribution of Demographic and Traveling Characteristics by Script Level

\begin{tabular}{|c|c|c|c|c|c|c|}
\hline \multirow[b]{2}{*}{$\begin{array}{l}\text { Demographics \& } \\
\text { traveling characteristics }\end{array}$} & \multicolumn{3}{|c|}{ Standardized script level } & \multicolumn{3}{|c|}{ Customized script level } \\
\hline & $\begin{array}{c}\text { Relaxation } \\
\text { of script }\end{array}$ & $\begin{array}{l}\text { Moderately } \\
\text { scripted }\end{array}$ & $\begin{array}{l}\text { Predominantly } \\
\text { scripted }\end{array}$ & $\begin{array}{c}\text { Relaxation } \\
\text { of script }\end{array}$ & $\begin{array}{l}\text { Moderately } \\
\text { scripted }\end{array}$ & $\begin{array}{l}\text { Predominantly } \\
\text { scripted }\end{array}$ \\
\hline \multicolumn{7}{|l|}{ Age } \\
\hline 40 years old or less & 9 & 27 & 13 & 11 & 21 & 11 \\
\hline Over 40 years old & 54 & 81 & 49 & 33 & 85 & 55 \\
\hline \multicolumn{7}{|l|}{ Gender } \\
\hline Male & 19 & 35 & 19 & 20 & 31 & 23 \\
\hline Female & 44 & 72 & 43 & 24 & 75 & 43 \\
\hline \multicolumn{7}{|l|}{ Education } \\
\hline College degree or less & 46 & 74 & 44 & 32 & 71 & 51 \\
\hline Graduate degree & 17 & 34 & 18 & 12 & 35 & 15 \\
\hline \multicolumn{7}{|l|}{ Income } \\
\hline \$50K or less & 16 & 33 & 16 & 14 & 21 & 15 \\
\hline$\$ 50,0001$ to $\$ 125 \mathrm{~K}$ & 28 & 52 & 32 & 22 & 58 & 34 \\
\hline More than $\$ 125 \mathrm{~K}$ & 12 & 17 & 10 & 7 & 19 & 12 \\
\hline \multicolumn{7}{|l|}{ Frequency of travel } \\
\hline Not frequent & 39 & 71 & 34 & 30 & 55 & 42 \\
\hline Frequent & 28 & 39 & 29 & 16 & 53 & 27 \\
\hline \multicolumn{7}{|l|}{ Reason for travel } \\
\hline Business & 14 & 23 & 19 & 10 & 24 & 14 \\
\hline Leisure & 53 & 87 & 44 & 37 & 84 & 56 \\
\hline
\end{tabular}




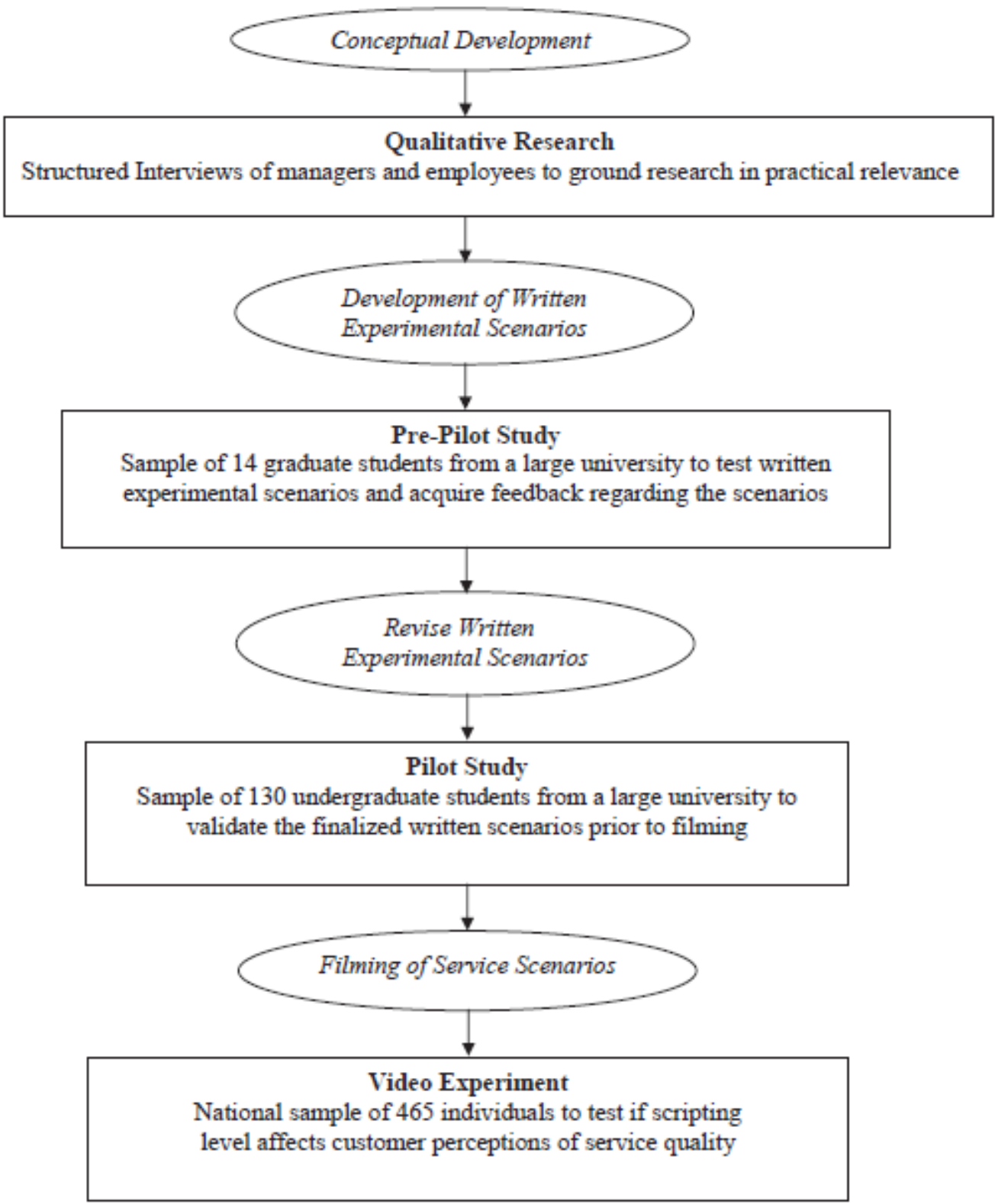

Figure 1. Experimental Development Research Phases 